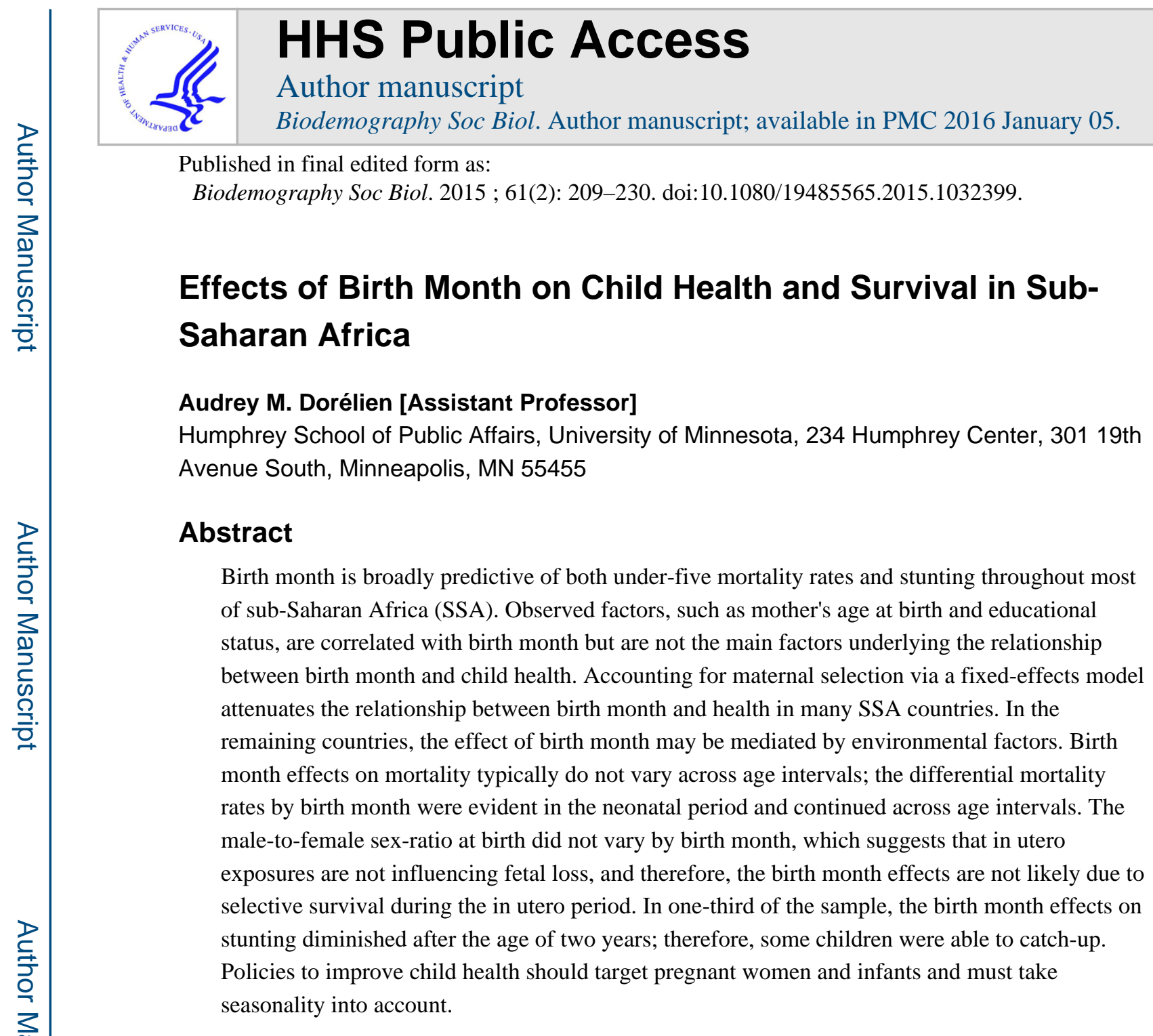

\title{
INTRODUCTION
}

Sub-Saharan Africa (SSA) presents some of the highest under-five mortality rates (U5MR) in the world. As of 2012, there were 98 deaths under age five per 1000 live births in SSA. This represents significant progress since 1990 but is far from the Millennium Development Goal (MDG) of 59 deaths per 1000 by 2015 (UNICEF's Division of Policy and Strategy, 2013). Thirty-four percent of the under-five deaths occur in the neonatal period and result from preterm births, delivery-related complications and infections. During infancy and childhood, the leading causes of death are pneumonia, diarrhea, and malariai; malnutrition is an important underlying factor (UNICEF's Division of Policy and Strategy, 2013). The seasonal nature of infectious causes of death (Brewster and Greenwood, 1993; Ye et al., 2009) and the large numbers of neonatal deaths highlight the need to study the influence of seasonal and early life exposures on child mortality. I address this gap by quantifying and

Appendix A. List of countries and survey years included in analysis.

Appendix B. Full regression results for all four survival models for the 30 countries in the sample. Appendix C. Full regression results for all three logistic models for the 29 countries in the sample.

${ }^{\mathrm{i}}$ Historically, measles was also a leading cause of childhood deaths, but its contribution has declined significantly in the last decade. 
analyzing the relationship between birth month (i.e., a proxy for early life conditions) and child health in SSA. I attempt to identify whether birth month is a proxy for events that occur at conception, in utero, or during infancy or whether the effect associated with birth month is due to confounding by gestational age, an unobserved factor. This research is particularly significant in light of the ongoing increase in high-priority child health interventions taking place as a result of the MDGs.

\section{Existing literature}

A well-established literature demonstrates birth month and early-life conditions are predictive of health later in life (Curhan et al., 1996; Moore et al., 1997; Doblhammer and Vaupel, 2001; Barker et al., 2002; Gluckman et al., 2008; Huber et al., 2004; Torrey et al., 1997; Bengtsson and Lindström, 2003; McEniry, 2011). Fewer studies have analyzed the impact of birth month on early-life outcomes, such as infant and child mortality and stunting, and fewer yet have focused on developing regions such as SSA (Eastman, 1945; Breschi and Livi-Bacci, 1997; Muñoz-Tudurí and García-Moro, 2008; Lokshin and Radyakin, 2012).

In developed countries, birth month is predictive of infant and child health. In a study using data from the late 1930s, American infants born in winter experienced higher infant mortality rates than those born in summer (Eastman, 1945). However, due to selective survival, if a winter baby survived the first few months, they were more likely to survive to age one. Recent studies based on historical data from Europe have also documented differential infant survival probabilities by birth month, although the magnitude of the effect varied by region (Breschi and Livi-Bacci, 1997; Muñoz-Tudurí and García-Moro, 2008). Birth month remains predictive of early-life health in developed countries; Currie and Schwandt (2013) used contemporary data and found that New England infants born in the spring had higher birth weights, after controlling for gestational length, than those born in the winter.

The findings from developing countries are mixed. In the Gambia, researchers found a relationship between birth month and infectious disease mortality but only for individuals older than 15 years (Moore et al., 1997), while in Mozambique, infant survival probabilities vary with birth month (Artadi, 2005). Among Indian children, no relationship between birth month and survival to age three was identified, but there was a statistically significant relationship between birth month and stunting (Lokshin and Radyakin, 2012). ${ }^{\text {ii }}$

\section{Possible mechanisms for birth month effects on health}

Potential explanations for the effect of birth month fall into the following four categories: 1) Births within a year may not be randomly distributed across the population because, for instance, seasonal fertility patterns vary by socioeconomic status (Buckles and Hungerman, 2012); 2) The month of conception affects fetal nutritional inputs and seasonal exposures; 3 )

\footnotetext{
${ }^{\text {ii }}$ A child is considered stunted if his/her height-for-age is more than two standard deviations below the mean in the World Health Organization's reference population. Malnutrition, infections, stress, and genetic disorders can all lead to stunting. Height faltering is usually observed after the weaning period and is thought to be indicative of chronic malnutrition and disease status; therefore, it does not fluctuate widely over time. However, stunting can have its antecedents in fetal development; in those cases, it is typically described as small for gestational age (McCowan et al., 1999; Maleta et al., 2003).
} 
birth month is also associated with different postpartum exposures in terms of disease and nutrition (Eastman, 1945; Bengtsson and Lindström, 2003); and 4) when data on gestational age is not available, the estimated birth month effect could be confounded by an interaction between conception rate seasonality and the distribution of gestational ages (Currie and Schwandt, 2013).

\section{Differences at conception: Influence of socio-demographic characteristics-}

Much of the literature on birth month and later life outcomes assumes that births in a given month are randomly distributed across all segments of the population. However, demographic covariates such as maternal education and birth order and spacing influence early childhood mortality and stunting (Mosley and Chen, 1984; Madise et al., 1999), and it is possible they are also correlated with birth month. If so, they may be driving at least part of the relationship between birth month and health (Hobcraft et al., 1985; Buckles and Hungerman, 2012; Brown, 2011); children born in different months may be different at conception. For instance, in the US, controlling for a mother's socio-demographic characteristics can explain up to half of the relationship between birth month and certain later life outcomes (Buckles and Hungerman, 2012). One way to control for the influence of selection is to follow the same mothers over time and compare the outcomes of siblings born in different months to the same mother (Currie and Schwandt, 2013).

\section{Differences in prenatal conditions: Fetal origins hypothesis}

Adaptive response: One perspective posits that during development, the fetus may adjust its physiology and metabolism as a response to cues from the mother regarding the external environment. One of the most cited developmental responses, termed the thrifty phenotype (i.e., reduced fetal growth), is believed to be an adaptive response by the fetus to nutritional stress (Gluckman et al., 2008; Kuzawa and Quinn, 2009). In this case, seasonal metabolic adjustments could result in increased infant survival, and we may not find a birth month effect on mortality before adulthood.

Non-adaptive effects: Poor maternal conditions such as malnutrition, disease, and stress during critical periods of gestation may impair fetal growth. Therefore, changes in fetal development may simply reflect developmental constraints, which can later impact health in early childhood and adulthood (Barker et al., 2002; Bateson et al., 2004; Lummaa, 2003). In cases in which normal development may be impaired, negative effects of the altered phenotype may appear early. For example, in temperate zones where rubella incidence is seasonal, birth month may affect the risk of congenital rubella syndrome (Miller et al., 1982). Information on birth weight, a proxy for prenatal conditions, could help us identify whether exposures in utero or during infancy are responsible for the birth month effects; if birth weight attenuates the relationship between birth month and child development and mortality, then the birth month effect is most likely due to prenatal conditions.

Researchers have also tested for the presence of adverse in utero conditions by looking at the ratio of male-to-female live births, termed the secondary sex ratio (Hansen et al., 1999; Catalano et al., 2006, 2009; Bruckner and Catalano, 2007). In the presence of adverse 
maternal conditions, the ratio of male-to-female live births declines due to an increase in male fetal loss.

Differences in postnatal conditions-A population's age-specific mortality profile may vary by birth month due to interactions between climate, disease, socio-cultural behaviors (e.g., seasonality in breastfeeding (González-Chica et al, 2012)), and the age at which a child experiences various seasons. For instance, due to the interactions between waning maternal immunity and seasonal fluctuations in disease risk, a child born at the peak of a measles outbreak may be better protected than a child born a few months prior, especially in areas with low vaccination coverage (Breschi and Livi-Bacci, 1997; Victora et al., 1987).

Confounding due to missing gestational age information-Studies that analyze the relationship between birth month and health outcomes without controlling for gestational age might identify seasonal relationships simply due to confounding (Currie and Schwandt, 2013). For instance, the period that falls nine months after the peak in conceptions may be associated with better infant health outcomes because, on average, there will be fewer preterm births during that month; the preterm children conceived nine months before would have been born seven and eight months after conception.

\section{Hypotheses}

I hypothesize that birth month will be predictive of child mortality and health in SSA but, a priori, do not have enough information to hypothesize which birth months will be associated with adverse outcomes. Given the large proportion of under-five deaths occurring during the neonatal period, I also hypothesize that differences in mortality by birth month will be apparent within the first month of life. In many SSA countries, women of different socioeconomic and demographic backgrounds have different seasonal fertility patterns (Dorelien, 2013); therefore, part of the birth month effect in SSA may be due to women's choices regarding when to conceive (i.e., maternal selection). If there are birth month effects on rates of stunting, I hypothesize that the stunted children were born small for their gestational age or experienced health shocks early in life and never caught up.

\section{DATA AND METHODS}

I used Demographic and Health Surveys (DHS) data collected from 30 SSA countries. Information on survey years included in the analysis can be found in Appendix A (contact author for copies of appendices). The DHS are nationally representative surveys of women of childbearing age (i.e., 15-49 years) carried out in developing countries and are well suited for conducting analyses on child mortality and health. In addition to containing complete reproduction histories from women (i.e., birth month and year of each child), they are also asked if the child is still living. If the child has died, the age at death is ascertained. Anthropometric measurements of height and weight for children under age five $\mathrm{e}^{\mathrm{iii}}$ were also

\footnotetext{
iii The Cox PH is one of the few survival models that can incorporate both random-effects and fixed-effects. To run a fixed-effects model, I stratified the data by maternal identity and removed variables that were fixed for mothers over time (Skrondal and RabeHesketh, 2012).
} 
collected during most surveys. In this study, I used the Birth Recode Files in which there is one record for every child ever born to the interviewed women. The dataset includes births from the 1980s to the mid 2000s; the specific time periods covered vary by country.

The DHS also contain data on individual and family characteristics, which may affect the relationship between birth month and child health and survival. These include information on sex, birth order, birth interval, rural/urban classifications, the age at which the mother gave birth, the mother's education level, and religion (Mosley and Chen, 1984; Hobcraft et al., 1985; Cleland and van Ginneken, 1988; Miller et al., 1992). For children born within five years of the survey date, information on subjective size at birth based on the mother's recollection and birth weight were also available.

\section{Data quality}

Survey data only contain information on the births of children whose mothers have not died between the time of birth and the interview date. There are also potential issues with misreporting of birth dates, misreporting of age at death, and event under-reporting. To limit recall bias, I limited the analyses to births in the ten years prior to the survey date. The DHS imputes birth dates to address incomplete observations (Arnold, 1990). Observations with an imputed birth month and/or birth year are excluded from our sample. The proportion of observations with imputed birth dates ranged from less than one percent to 43 percent across countries; on average, eight percent of the observations were dropped (Table 1). The observations with imputed birth dates were more likely to be composed of older and dead children from rural areas and of children born to uneducated mothers. I do not expect that underreporting will bias the relationship between birth month and mortality, but it could lead to an underestimation of the birth month effect. I am particularly concerned with misreporting of the age at death. Observations that were missing information on age at death were not included. Less than one percent of deaths were excluded in all countries except Nigeria and South Africa, where 1.26 and 5.73 percent of deaths were excluded, respectively.

Birth weight information was missing for most individuals in the sample (Table 2). The variable "small at birth" was used in the stunting analyses but might also suffer from data quality issues. A child was considered "small at birth" if the mother deemed the child "smaller than average" or "very small" at birth. Based on analyses of DHS data from three different countries, Channon (2011) found that maternal perception of size is a good proxy for birth weight. I tabulated the mean birth weight by maternal recall size and found that for every country in my sample, mean birth weight increased monotonically with recalled size, and smaller than average and very small babies had a mean birth weight close to or below the 2,500 gram cutoff. Nonetheless, the variable "small at birth" is not a perfect indicator of low birth weight (LBW) (Robles and Goldman, 1999; Boerma et al, 1996). There are conflicting results regarding wither relative size under- or overestimates LBW. In my dataset, "small at birth" did not consistently capture all or most LBW infants, indicative of some individual-level error. 


\section{Conceptual Issues}

There are other limitations of the DHS data. It contains no information on gestational length. To deal with this, I assume that each individual was conceived nine months prior to birth. This is problematic if many births have seven or eight month gestations and conception rates vary seasonally. In SSA, preterm birthrates range from 10.1 per 100 live births in Western Africa to 17.5 per 100 in Southern Africa (Beck et al., 2010); in addition, high levels of birth seasonality, and therefore likely conception seasonality, have been documented (Dorelien, 2013). Consequently, by conducting the analysis at the level of birth month, the results may be biased. In particular, in places with high birth seasonality, the birth month effect might be overestimated.

Estimation Strategies-All analyses were carried out using STATA Statistical Software version 12 (StataCorp, 2011). Separate analyses were run for each of the 30 SSA countries. Country-specific analyses were performed primarily due to strong heterogeneity in SSA. Birth month is a proxy for many ecological and socio-cultural factors that affect health; in different countries, it may reflect different factors. Even if two countries share the same ecological space, the interactions between the socio-cultural and ecological factors likely create unique country-specific seasonal patterns in birth month effects on health.

Additionally, national patterns are themselves of interest and allow comparisons with results from previous studies.

With the data available in the DHS, I test the significance of birth month effects by running joint significance tests on all my models. I test whether maternal selection drives seasonality in health outcomes and identify how birth month effects vary across age (pre and post natal), a stepping-stone to identifying the factors underlying birth month effects on health.

\section{Testing for birth month effects on selective survival in utero}

The sex ratio at birth has been used as an indicator of selective survival in utero. To test whether the ratio varied by birth month, I regressed the proportion of male births against birth month indicator variables while controlling for birth order, duration since the mother's previous pregnancy, mother's age at birth, maternal education level, type of residence, and religion. The regression also included standard errors clustered at the mother level.

\section{Testing for birth month effects on childhood survival}

The relationship between birth month and mortality may vary across age intervals (Eastman, 1945; Breschi and Livi-Bacci, 1997; Muñoz-Tudurí and García-Moro, 2008). To address this concern and due to the discrete nature and censoring of our data, the first set of survival analyses relied on a flexible piecewise exponential hazard (PWE) model to determine the association between birth month and mortality across ages. The intervals over which I assumed the hazard to be constant were less than 1 month, 1 to 5 months, 6 to 11 months, 12 to 23 months, 24 to 35 months, 36 to 47 months, and 48 to 59 months. I first used a piecewise model with age intervals and birth month to generate hazards for each combination of birth month and age interval. The resulting hazards were used to calculate survival probabilities as well as U5MR. Next, I used a likelihood ratio test to compare the fit of models with and without interactions between birth month and age interval. For the 
majority of the countries, there were no significant interactions between birth month and age-specific hazards. For the remainder of the survival analyses, I used Cox Proportional Hazard ( $\mathrm{PH})$ models, which produce similar results to the PWE models and have the advantage of allowing for a fixed-effects approach. ${ }^{\text {iii }}$

Cox PH Model 1, the baseline model, only accounts for birth month. I used these models to demonstrate seasonal variations in the effect of birth month on health across SSA. In Cox PH Model 2, I controlled for individual characteristics (i.e., birth order, sex, and birth interval). In Cox PH Model 3, I additionally controlled for maternal and family characteristics (i.e., Model 2 plus mother's age at birth, mother's education level, religion, agricultural or non-agricultural household, and rural versus urban residence). In Cox PH Model 4 (i.e., Model 2 plus mother's age at birth), I used a fixed-effects approach, stratifying by mother's identity (Skrondal and Rabe-Hesketh, 2012). I was therefore able to control for unobserved characteristics associated with having the same mother but could only use a small fraction of the data to estimate the covariates.

\section{Testing for birth month effects on stunting}

To assess the relationship between birth month and stunting, I relied on anthropometric measurements of surviving children born within five years of the survey date. In the first logistic regression model (i.e., the individual model), I calculated the odds of being stunted while controlling for birth month, sex, birth order, small-size at birth, and age. The second logistic regression model included variables related to maternal and family characteristics (as in Cox PH Model 3). The third model (i.e., the full model) was a fixed-effects model with individual-level controls and controls for mother's age at birth; the fixed-effects model took into account additional unobserved family characteristics. Another regression (i.e., Model 2 with interactions between birth month and a variable for children above age two) tested whether the birth month effect on stunting varied across ages. To facilitate the interpretation of the model results, I calculated the marginal effects (i.e., the differences in the predicted probabilities) of each of the covariates using marginal standardization (Muller and MacLehose, 2014).

\section{RESULTS}

\section{Summary Statistics}

Table 1 contains summary statistics for the children included in the mortality analysis. Across SSA countries, substantial variation exists with respect to under-five mortality, fertility, maternal education, fraction of agricultural and urban households, and religion. The countries with the highest U5MR tend to be located in the Sahel, while those with the lowest U5MR are located in Southern Africa.

Table 2 presents summary statistics for the children included in the stunting analysis. Unlike the sample described in Table 1, this sample only included children who were alive at the time of the survey. In comparison with the first sample, there was a slightly higher proportion of females, which might reflect higher male mortality rates; mothers were also more likely to be educated and less likely to be from agricultural households. 


\section{Sex Ratio at Birth Results}

The ratio of male-to-female live births did not vary by birth month except in South Africa and perhaps Uganda.

\section{Survival Analysis Results}

Quantifying the birth month effect on child survival-Based on output from the PWE survival model with interactions between birth month and age interval, I calculated the cumulative survival probabilities and converted the survival probabilities to U5MR. Figure 1 lists the U5MR for the months with the highest and lowest cumulative survival probabilities. Differences between the extreme months (i.e., worst versus best birth month) could be large. On average, the U5MR in the worst birth month were 39 percent higher than in the best. In Sierra Leone, Ivory Coast, and Zimbabwe, the differences were greater than 60 percent. I regressed the difference between the U5MR for best and worst month with a measure of data quality (Table 1) and did not find any significant results $(\mathrm{R}$-squared $=0.0387)$.

The PWE models with birth month and age interactions were statistically significantly better in only six countries: Burkina Faso, D.R. Congo, Ivory Coast, Niger, Nigeria, and Tanzania. Therefore, in the majority of SSA countries, birth month effects were relatively constant across age intervals. In Figure 2a, I show the survival curves for six typical countries, and in Figure $2 b$, the survival curves for the six countries where birth month and age interactions were significant. Figure 2a illustrates that the birth month effect is often evident during the neonatal period and does not diminish with age.

For the remainder of this section, the results presented are from the Cox PH models. Full regression results for each of the Cox $\mathrm{PH}$ models with estimates for all the covariates can be found in Appendix B. Figure 3 is a heat map of the hazard ratio for each birth month relative to the reference month from the model without individual- or maternal-level controls (i.e., Cox PH Model 1). The countries are sorted from north to south and east to west. The birth month hazard ratios ranged from 1 (white) to a little over 2 (black). The p-values from the joint significance test on birth months are shown on the right axis. Birth month was jointly significant and predictive of survival to age five in every country sampled except the majority of those in Southern Africa (i.e., Namibia, Swaziland, South Africa, and Lesotho); these countries had the lowest child mortality rates. Birth month was not jointly significant in Cameroon, Congo or Togo either. Additionally, in the aforementioned Southern African countries and in Togo, seasonal fluctuations in births were not significant (Dorelien, 2013).

There were other geographic patterns present in the mortality results. For example in the Sahelian countries, the first three months of the year exhibited the highest survival probabilities (Figure 3). Overall, the patterns in the heat map indicate a great deal of seasonal variation in the effect of birth month on health.

Controlling for individual level covariates and maternal selection-In the majority of SSA countries, controlling for known characteristics resulted in small shifts in the pattern and magnitude of the birth month hazard ratios (Figure 4; see legend for Cox PH Models 2 and 3, Appendix B). Furthermore, the birth month effects remained significant in 
most countries. However, after controlling for maternal selection (i.e., using a fixed-effects model), the birth month effect remained statistically significant in only one-third of the SSA countries sampled. Birth month remained predictive of survival to age five in Chad, D.R. Congo, Ghana, Guinea, Kenya, Mali, Nigeria, Sierra Leone, Uganda, Zambia, and Zimbabwe (Figure 4). Some of these countries had relatively low levels of U5MR (e.g., Kenya and Zimbabwe), while others had high levels (e.g., Chad and Mali). In more than half of these countries, there was little variation in the birth month hazard ratio across the different models (i.e., controlling for individual and family characteristics resulted in small shifts in the pattern and magnitude of birth month hazard ratios); this suggests that maternal selection does not explain the birth month effect on child survival. In Ghana and Zimbabwe, hazard ratios calculated from the birth month coefficients increased after controlling for maternal selection, which indicates that in these countries, maternal selection might have been masking seasonality in birth month effects on health. In Guinea, controlling for maternal selection altered the seasonal pattern of birth month effects on health; while June remained the birth month associated with the greatest child mortality, February was no longer associated with the highest level of child survival (Figure 4).

After controlling for maternal selection, the birth month effect was no longer jointly significant in Benin, Burkina Faso, Cameroon, Ethiopia, Liberia, Madagascar, Malawi, Mozambique, Senegal, or Tanzania. In these countries, maternal selection and therefore unobserved differences at conception might be responsible for the seasonal patterns in birth month effects on health. The joint tests for birth month were marginally significant in Ivory Coast, Niger, and Rwanda. The birth month effects remained jointly insignificant in Southern Africa, Congo, and Togo.

\section{Stunting}

Quantifying the birth month effect on stunting-Based on the model with individual-level controls, the predicted probability of being stunted varied by birth month, and the differences were statistically significant. Figure 5 contains a heat map of the marginal effects for each birth month relative to a reference month. The countries are sorted by latitude and longitude (y-axis) and birth month (x-axis). The p-values from the joint significance tests are on the right axis. The colors represent the marginal effect compared to the birth month with the lowest probability of being stunted. The marginal effects ranged from 0 (white) to slightly above 12 (black) percentage points. On average, there was a 7percentage point difference in the predicted probability of being stunted between children born in the month associated with the highest rate of stunting and those born in the month with the lowest rate (i.e., the best month). The predicted probabilities of being stunted for children born in the best birth months are listed in parentheses (Figure 5).

Some countries stood out on the heat map. In Senegal, which has the lowest rates of stunting, the difference in the predicted probabilities between the worst (April) and best (February) birth month was only 3.4 percentage points. The marginal effect of birth month was also small in Nigeria, where rates of stunting are large. The magnitudes of the birth month effects were very large in Chad, Congo, Liberia, Malawi, and Niger (Figure 5, 
Appendix C). The joint significance test revealed that in Cameroon, Ivory Coast, Lesotho, Sierra Leone, and Swaziland, birth month effects were not significant.

There also appears to be a spatial pattern in the effect of birth month on stunting. For instance, in Sahelian countries (i.e., Mali, Niger, Chad, and Burkina Faso), the birth months associated with the lowest probability of stunting are November and December, which immediately follow the short rainy season (Figure 5). In Tanzania and Malawi, the birth months associated with the highest levels of stunting occur during the rainy season just before harvest (i.e., hunger season, January-March), and the months with the lowest levels occur in the post-harvest dry season (i.e., August-October) (Mitchell, 2003).

The birth month effects are comparable to other well-known determinants of child stunting. For instance, in Zambia, the marginal effect of a child being stunted if he/she was born in January or February is 6 percentage points higher than if he/she was born in the last three months of the year (Appendix C). This effect size is larger than the difference in the predicted probabilities for males and females (i.e., 3.5 percentage points).

Size at birth, birth month and age interactions-Infants who were considered small at birth were significantly more likely to be stunted at the time of the survey than other infants (Appendix C). However, controlling for infant size did not attenuate or eliminate birth month effects. The birth month effect was stronger in children under age two years than in those over two in Benin, Congo, DR Congo, Ghana, Kenya, Malawi, Niger, Nigeria, Tanzania, and Zimbabwe, which suggests children are able to compensate for the lack of early growth (regression not shown). In Mali, Rwanda, and Zambia, the birth month effects were much stronger for children over age two. In Ethiopia, Madagascar, and Guinea, the interactions between birth month and age were significant but varied in direction. In the remaining half of the countries in the sample, birth month effects did not vary significantly by age.

Controlling for observed and unobserved maternal selection-By looking at the marginal effects, I was able to compare the effect of birth month across various nested logistic models. There were no large differences in the marginal effects between the model with individual-level controls and the model controlling for observed maternal selection (Figure 6). However, controlling for unobserved selection using the fixed-effects model yielded significant changes. For the majority of countries where the birth month effect was significant in the individual model, controlling for unobserved maternal selection significantly damped the seasonality of the birth month effects on stunting. After running the fixed-effects model, birth month remained jointly significant in only five countries-Zambia and Malawi (i.e., the countries with the highest rates of stunting) and Benin, Madagascar, and Tanzania (countries with high rates of stunting) (Figure 6).

\section{DISCUSSION AND CONCLUSION}

In SSA, birth month is broadly predictive of child health and survival. There are large and significant differences among the probabilities of dying by age five or being stunted according to birth month. The magnitudes of the birth month hazard ratios and marginal 
effects were often comparable to the health advantages of urban living or being female (Appendix B and C).

One important caveat is that, because the analysis was conducted at the level of birth month and not conception month, the magnitude of the birth month effect on health is most likely overestimated, especially when the peak birth month corresponds with the healthiest birth month in countries with high degrees of birth seasonality. Based on findings by Dorelien (2013), the largest fluctuations in births occurred in West and Central Africa (i.e., Sierra Leone, Guinea, DR Congo, Nigeria, Rwanda, Mozambique). For example in DR Congo, the peak birth months are also the birth months associated with the highest survival probabilities.

Although family background is related to birth month, controlling for known sociodemographic factors did not account for a large amount of the birth month effect on child health. In contrast, controlling for unobserved maternal selection did significantly dampen or eliminate the birth month effects on health in many countries. In these cases, children born in different months were already different at the time of conception. In countries where maternal selection did not eliminate the effects of birth month on childhood health, the effects are most likely mediated by environmental factors that influence pre- or post-natal nutrition or disease status. Future work should try to unpack the factors behind the birth month effect, but more data will be needed.

The survival analysis results indicated that differences in survival associated with birth month were present in the neonatal period and were relatively constant across age intervals. This suggests that differences at conception and or seasonal exposures in utero are most likely responsible for the birth month effect. This is in contrast to studies that have found differential effects of birth month across age intervals and attributed the birth month effects on neonatal mortality to in utero processes and the birth month effects on post-neonatal mortality to differential environmental factors during infancy (Eastman, 1945; MuñozTudurí and García-Moro, 2008). We should prioritize interventions aimed at pregnant women and infants, and policies aimed at improving infant health through supplemental feeding of pregnant women should take seasonality into account.

The stunting analysis also indicated that seasonal exposures in utero or early in infancy might be responsible for the birth month effects. In one-third of the sample, the birth month effects on stunting diminished after age two; therefore, some children were able to catch up. Only in Mali, Rwanda, and Zambia were the birth month effects considerably stronger for children over age two. One explanation for this is that children born during certain months might already be disadvantaged at birth, but during weaning, the pre-existing disadvantage is exacerbated. The ratio of male-to-female live births did not vary by birth month except in South Africa and perhaps Uganda. This suggests that in general, seasonal in utero exposures are not resulting in fetal loss, and therefore, the birth month effect is not likely due to selective survival during the in utero period. Similarly, I did not find evidence of postnatal selective survival (i.e., there was no reversal of the birth month effect across age groups). Nevertheless, in the presence of heterogeneity, weaker children may die earlier when born in low survival months and therefore, the remaining children born in low survival months may 
be more robust. This could lead to opposing effects of birth month on stunting and survival. In a few countries, such as Chad and Mali, there is evidence of this pattern of selective survival; the effects of birth month on survival and stunting were opposite (Figures 3 and 5).

\section{Supplementary Material}

Refer to Web version on PubMed Central for supplementary material.

\section{Acknowledgements}

I was supported by the National Institute for Child Health and Human Development, Grant No. R24HD047879, to the Office of Population Research at Princeton University. The funders had no role in study design, data collection and analysis, decision to publish, or preparation of the manuscript.

\section{REFERENCES}

Arnold, F. Technical report. Marco Systems Inc.; 1990. An assessment of DHS-I data quality..

Artadi, EV. Infant Survival in Rural Africa. Harvard University; 2005. Going into Labor: Earnings vs..

Baek D, Villén J, Shin C, Camargo FD, Gygi SP, Bartel DP. The impact of micrornas on protein output. Nature. 2008; 455(7209):64-71. [PubMed: 18668037]

Barker D, Eriksson J, Forsén T, Osmond C. Fetal origins of adult disease: strength of effects and biological basis. International Journal of Epidemiology. 2002; 31(6):1235-1239. [PubMed: 12540728]

Bateson P, Barker D, Clutton-Brock T, Deb D, D'Udine B, Foley RA, Gluckman P, Godfrey K, Kirkwood T, Lahr MM, McNamara J, Metcalfe NB, Monaghan P, Spencer HG, Sultan SE. Developmental plasticity and human health. Nature. 2004; 430(6998):419-421. [PubMed: 15269759]

Beck S, Wojdyla D, Say L, Betran AP, Merialdi M, Requejo JH, Van Look PF. The worldwide incidence of preterm birth: a systematic review of maternal mortality and morbidity. Bulletin of the World Health Organization. 2010; 88(1):31-38. [PubMed: 20428351]

Bengtsson T, Lindström M. Airborne infectious diseases during infancy and mortality in later life in southern Sweden, 1766-1894. International Journal of Epidemiology. 2003; 32(2):286-294. [PubMed: 12714551]

Blanc, Ann K.; Wardlaw, Tessa. Monitoring low birth weight: an evaluation of international estimates and an updated estimation procedure. Bulletin of the World Health Organization. 2005; 83(3):178185d. [PubMed: 15798841]

Boerma JT, Weinstein KI, Rutstein SO, Sommerfelt AE. Data on birth weight in developing countries: can surveys help? Bulletin of the World Health Organization. 1996; 74(2):209. [PubMed: 8706237]

Breschi, M.; Livi-Bacci, M. Infant and Child Mortality in the Past., chapter Month of Birth and Children's Survival. Oxford University Press; 1997. p. 157-173.

Brewster DR, Greenwood BM. Seasonal variation in paediatric diseases in the Gambia West Africa. Annals of Tropical Paediatrics. 1993; 13(2):133-146. [PubMed: 7687109]

Brown, R. The 1918 US influenza pandemic as a natural experiment, revisited. Duke University; Feb. 2011 Conference paper

Bruckner T, Catalano R. The sex ratio and age-specific male mortality: evidence for culling in utero. Am J Hum Biol. 2007; 19:763-773. [PubMed: 17676612]

Buckles K, Hungerman D. Season of birth and later outcomes: Old questions, new answers. Review of Economics and Statistics. 2012; 95(3):711-724. [PubMed: 24058211]

Catalano R, Bruckner T, Marks AR, Eskenazi B. Exogenous shocks to the human sex ratio: the case of September 11, 2001 in New York City. Hum Reprod. 2006; 21:3127-3131. [PubMed: 16936298]

Catalano R, Ahern J, Bruckner T, Anderson E, Saxton K. Gender-specific selection in utero among contemporary human birth cohorts. Paediatr Perinat Epidemiol. 2009; 23:273-278. [PubMed: 19775389] 
Channon AA. Can mothers judge the size of their newborn? Assessing the determinants of a mother's perception of a baby's size at birth. Journal of biosocial science. 2011; 43(05):555-573. [PubMed: 21676278]

Cleland JG, van Ginneken JK. Maternal education and child survival in developing countries: The search for pathways of influence. Social Science \& Medicine. 1988; 27(12):1357-1368. [PubMed: 3070762]

Curhan GC, Willett WC, Rimm EB, Spiegelman D, Ascherio AL, Stampfer MJ. Birth weight and adult hypertension, diabetes mellitus, and obesity in US men. Circulation. 1996; 94(12):3246-3250. [PubMed: 8989136]

Currie J, Schwandt H. Within-mother analysis of seasonal patterns in health at birth. Proceedings of the National Academy of Sciences. 2013; 110(30):12265-12270.

Doblhammer G, Vaupel J. Lifespan depends on month of birth. Proceedings of the National Academy of Sciences. 2001; 98(5):2934.

Dorelien AM. A time to be born: birth seasonality in sub-Saharan Africa. PSC Research Report No. 13-785. 2013

Eastman P. Infant mortality in relation to month of birth. American Journal of Public Health. 1945; 35(9):913. [PubMed: 18016226]

Ellison PT. Fetal programming and fetal psychology. Infant and Child Development. 2010; 19(1):620.

Gluckman PD, Hanson MA, Cooper C, Thornburg KL. Effect of in utero and early-life conditions on adult health and disease. New England Journal of Medicine. 2008; 359(1):61-73. [PubMed: 18596274]

González-Chica D, Gonçalves H, Nazmi A, Santos I, Barros AJD, Matijasevich A, Victora C. Seasonality of infant feeding practices in three Brazilian birth cohorts. International Journal of Epidemiology. 2012; 41(3):743-752. [PubMed: 22354916]

Gyimah SO. Cultural background and infant survival in Ghana. Ethnicity \& Health. 2006; 11(2):101120. [PubMed: 16595314]

Hansen D, Moller H, Olsen J. Severe periconceptional life events and the sex ratio in offspring: follow up study based on five national registers. BMJ. 1999; 319:548-549. [PubMed: 10463895]

Hobcraft J, McDonald J, Rutstein S. Demographic determinants of infant and early child mortality: A comparative analysis. Population Studies. 1985; 39(3):363-385.

Huber S, Fieder M, Wallner B, Moser G, Arnold W. Brief communication: Birth month influences reproductive performance in contemporary women. Human Reproduction. 2004; 19(5):10811082. [PubMed: 15121731]

Klein SL. The effects of hormones on sex differences in infection: from genes to behavior. Neuroscience \& Biobehavioral Reviews. 2000; 24(6):627-638. [PubMed: 10940438]

Kudamatsu, M.; Persson, T.; Stromberg, D. Weather and infant mortality in Africa. IIES, Stockholm University; 2012.

Kuzawa CW, Quinn EA. Developmental origins of adult function and health: Evolutionary hypotheses. Annual Review of Anthropology. 2009; 38:131-147.

Lokshin M, Radyakin S. Month of birth and children's health in India. Journal of Human Resources. 2012; 47:174-203.

Lozano R, Wang H, Foreman KJ, Rajaratnam JK, Naghavi M, Marcus JR, Dwyer-Lindgren L, Lofgren KT, Phillips D, Atkinson C, Lopez AD, Murray CJ. Progress towards millennium development goals 4 and 5 on maternal and child mortality: an updated systematic analysis. The Lancet. 2011; 378(9797):1139-1165.

Lummaa V. Early developmental conditions and reproductive success in humans: Downstream effects of prenatal famine, birthweight, and timing of birth. American Journal of Human Biology. 2003; 15(3):370-379. [PubMed: 12704713]

Madise NJ, Matthews Z, Margetts B. Heterogeneity of child nutritional status between households: A comparison of six Sub-Saharan African countries. Population Studies. 1999; 53(3):331-343.

Maleta K, Virtanen S, Kulmala T, Ashorn P. Timing of growth faltering in rural malawi. Archives of Diseases in Childhood. 2003; 88(7):574-578. [PubMed: 12818899] 
McCowan L, Harding J, Barker S, Ford C. Perinatal predictors of growth at six months in small for gestational age babies. Early Human Development. 1999; 56(23):205-216. [PubMed: 10636598]

McEniry M. Infant mortality, season of birth and the health of older Puerto Rican adults. Social Science \& Medicine. 2011; 72(6):1004-1015. [PubMed: 20980087]

Miller E, Cradock-Watson J, Pollock T. Consequences of confirmed maternal rubella at successive stages of pregnancy. The Lancet. 1982; 320(8302):781-784.

Miller JE, Trussell J, Pebley AR, Vaughan B. Birth spacing and child mortality in Bangladesh and the Philippines. Demography. 1992; 29(2):305-318. [PubMed: 1607054]

Mitchell TD, Hulme M, New M. Climate data for political areas. Area. 2002; 34:109-112.

Moore SE, Cole TJ, Poskitt EME, Sonko BJ, Whitehead RG, McGregor IA, et al. Season of birth predicts mortality in rural Gambia. Nature. 1997; 388(6641):434-434. [PubMed: 9242401]

Moore SE, Fulford AJ, Streatfield PK, Persson LA,",Prentice AM. Comparative analysis of patterns of survival by season of birth in rural Bangladeshi and Gambian populations. International Journal of Epidemiology. 2004; 33(1):137-143. [PubMed: 15075159]

Mosley WH, Chen LC. An analytical framework for the study of child survival in developing countries. Population and Development Review. 1984; 10:25-45.

Muller CJ, MacLehose RF. Estimating predicted probabilities from logistic regression: different methods correspond to different target populations. International Journal of Epidemiology. 2014 first published online March 5, 2014 doi:10.1093/ije/dyu029.

Muñoz-Tudurí M, García-Moro C. Season of birth affects short- and long-term survival. American Journal of Physical Anthropology. 2008; 135(4):462-468. [PubMed: 18186510]

Robles A, Goldman N. Can accurate data on birthweight be obtained from health interview surveys? International Journal of Epidemiology. 1999; 28(5):925-931. [PubMed: 10597993]

Skrondal A, Rabe-Hesketh S. Multilevel and Longitudinal Modeling Using Stata. Volume II: categorical responses, counts, and survival. 2012

Statacorp. Stata Statistical Software: Release 12. StataCorp LP; College Station, TX: 2011.

Statistics Division of the United Nations Department of Economic and Social Affairs. Technical report. United Nations; 2011. The Millennium Development Goals report 2011..

Torrey EF, Miller J, Rawlings R, Yolken RH. Seasonality of births in schizophrenia and bipolar disorder: a review of the literature. Schizophrenia Research. 1997; 28(1):1-38. [PubMed: 9428062]

Victora CG, Vaughan JP, Lombardi C, Fuchs SC, Gigante L, Smith P, Nobre L, Teixeira A, Moreira L, Barros F. Evidence for protection by breast-feeding against infant deaths from infectious diseases in Brazil. The Lancet. 1987; 330(8554):319-322.

UNICEF's Division of Policy and Strategy. Progress Report. United Nations Children's Fund; 2013. Committing to child survival: A promised renewed..

Ye Y, Zulu E, Mutisya M, Orindi B, Emina J, Kyobutungi C. Seasonal pattern of pneumonia mortality among under-five children in Nairobi's informal settlements. American Journal of Tropical Medicine and Hygiene. 2009; 81(5):770-775. [PubMed: 19861609] 


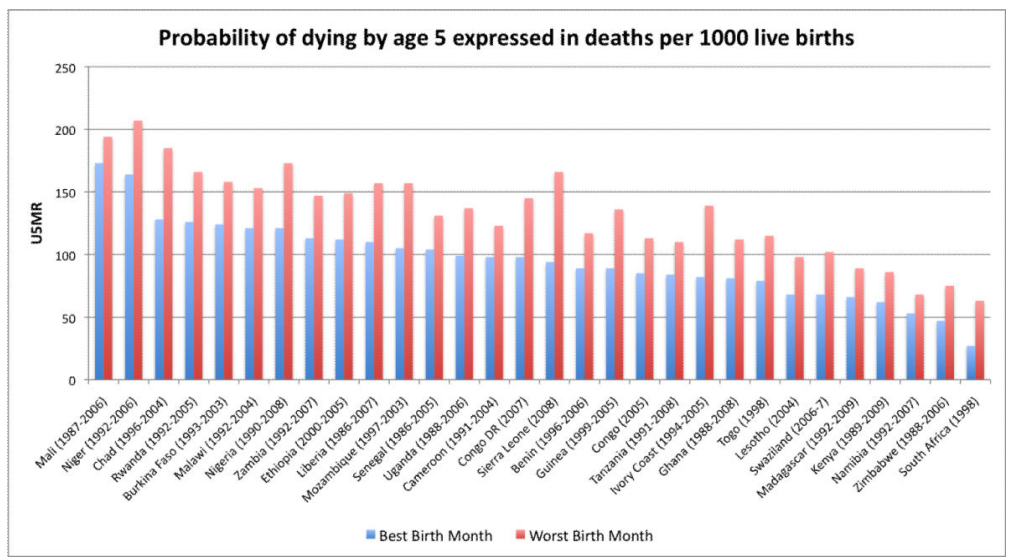

Figure 1.

Bar chart comparing the under-five mortality rates for best and worst birth months. Countries are ordered based on magnitude of under-five mortality rates. 
A
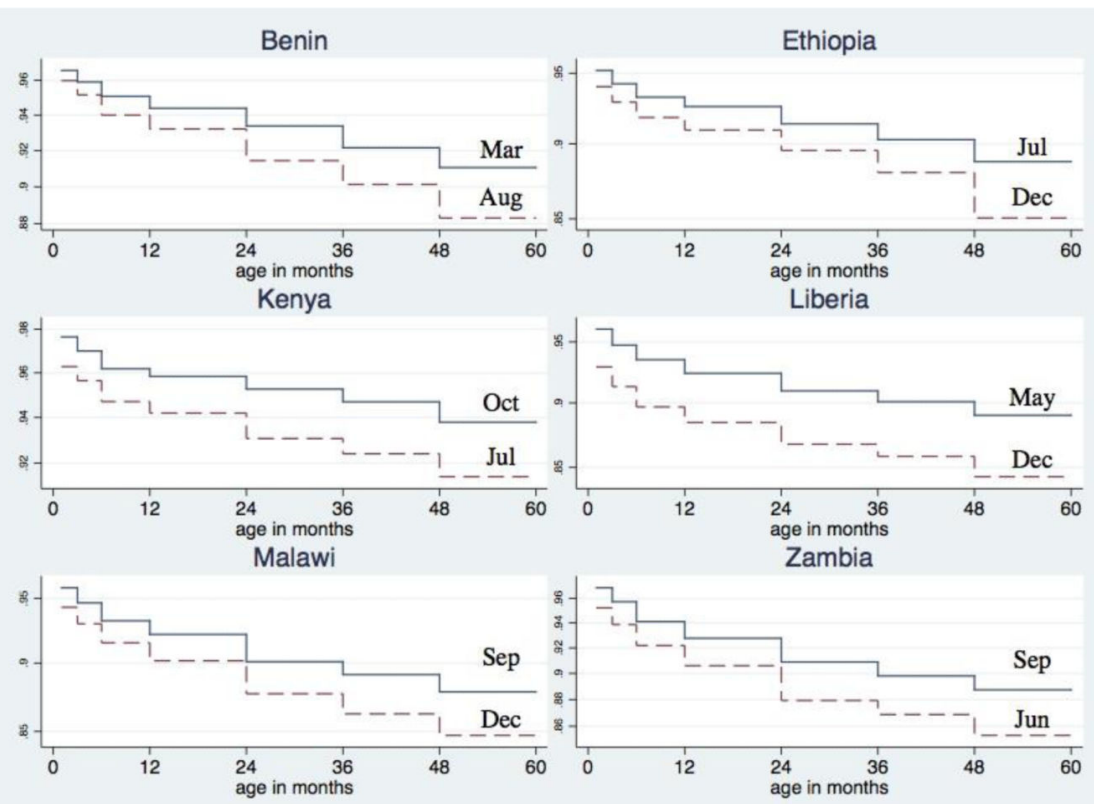

B
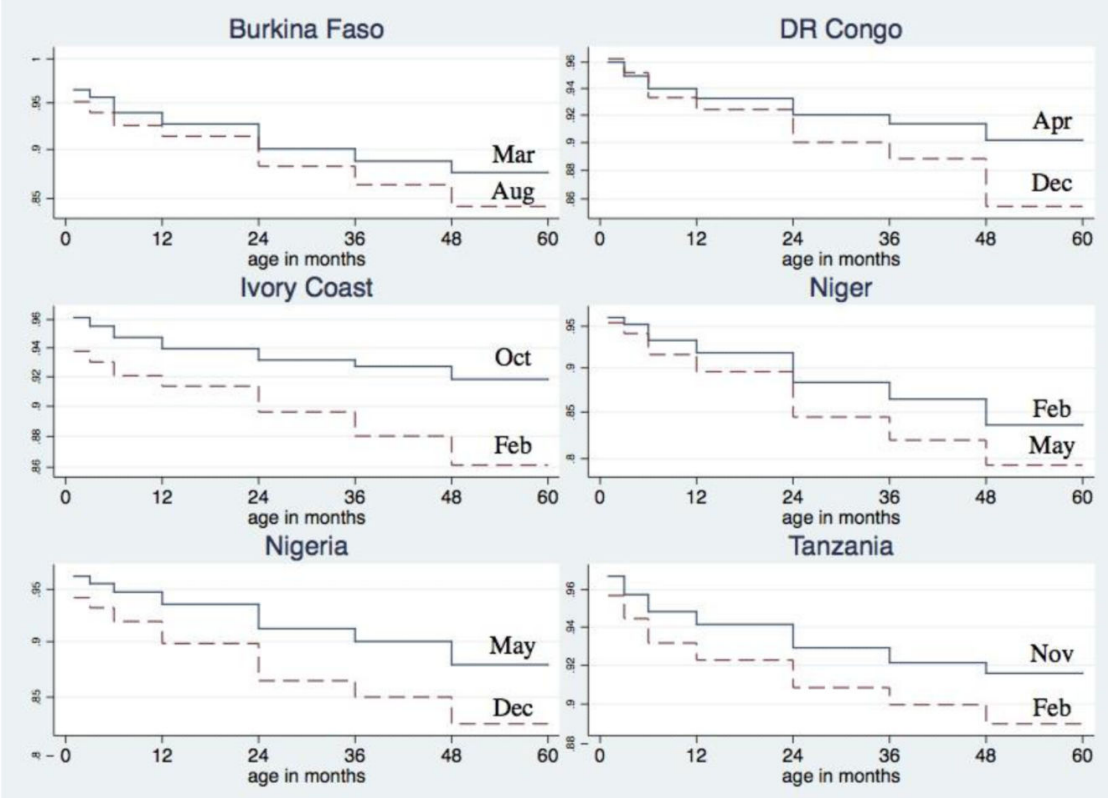

Figure 2.

Survival probability curves for best and worst birth months. Panel 2a contains survival curves for six typical SSA countries where the birth month effects were relatively constant across age intervals. Differences in mortality by birth month are evident in the neonatal period and persist until age five. Panel $2 \mathrm{~b}$ contains survival curves for the six countries where there were significant interactions between birth month and the age specific hazards. In these countries the birth month differences increased with age. 


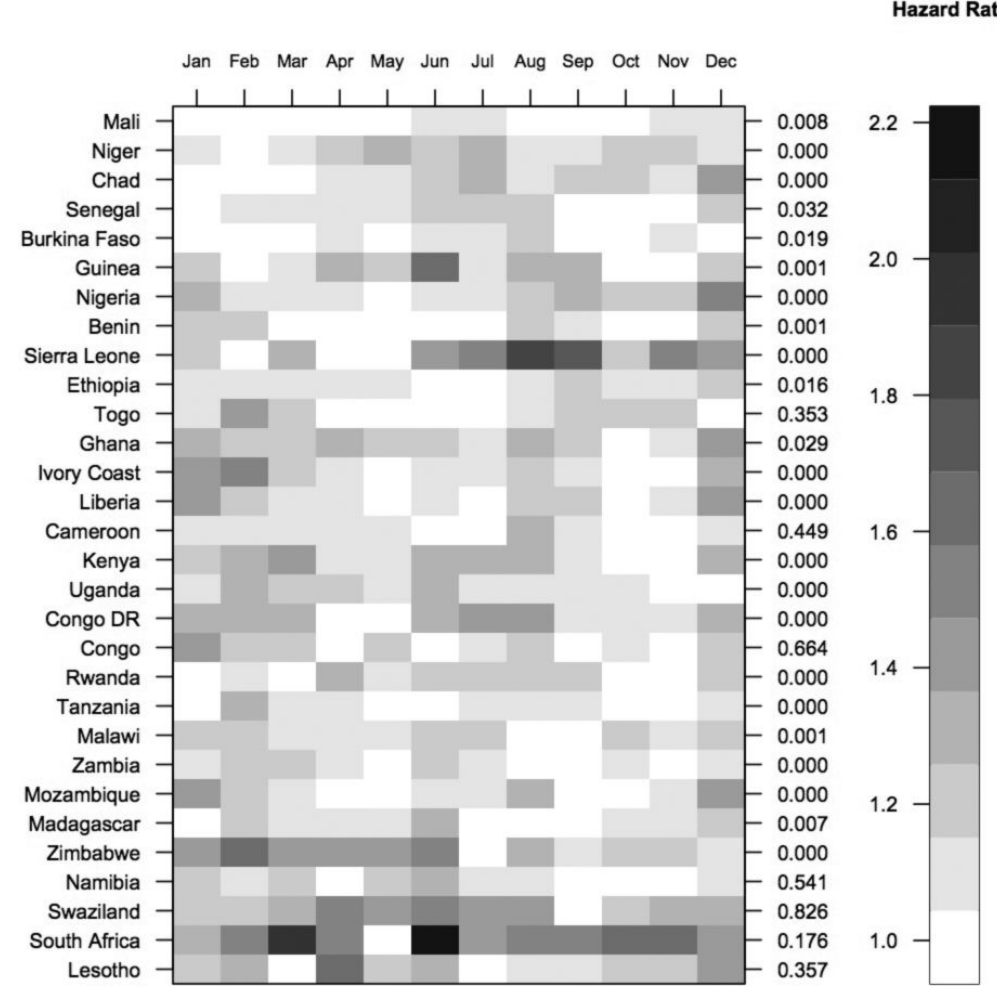

Figure 3.

Heat map showing hazard ratios for each birth month relative to a reference month. For each country, the reference month is the month associated with the lowest probability of dying by age five. Countries are ordered north/south and east/west. On the right axis are p-values from joint significance tests on birth months. 


\section{Chad}

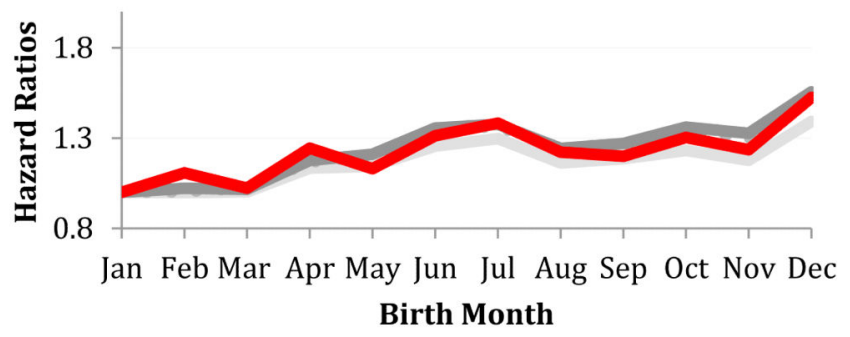

Ghana

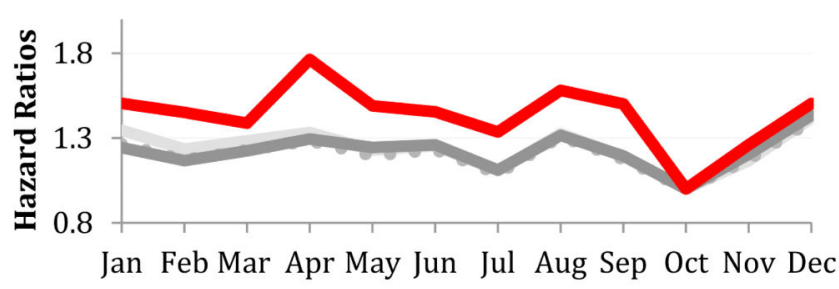

Birth Month

Kenya

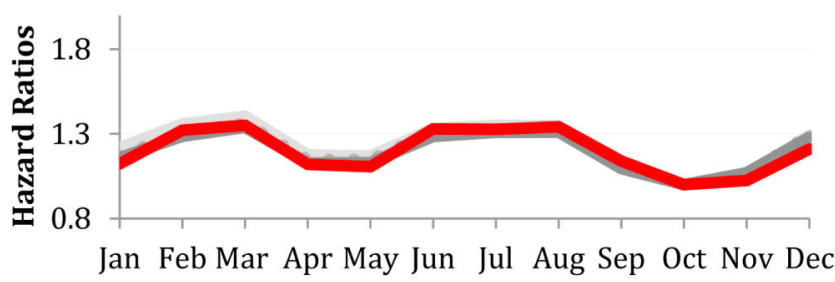

Birth Month

\section{DR Congo}

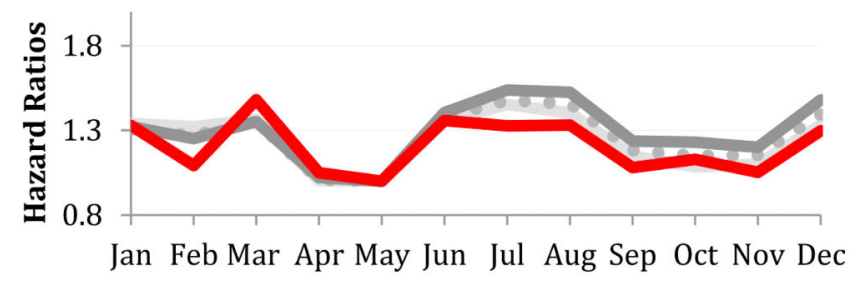
Birth Month

\section{Guinea}

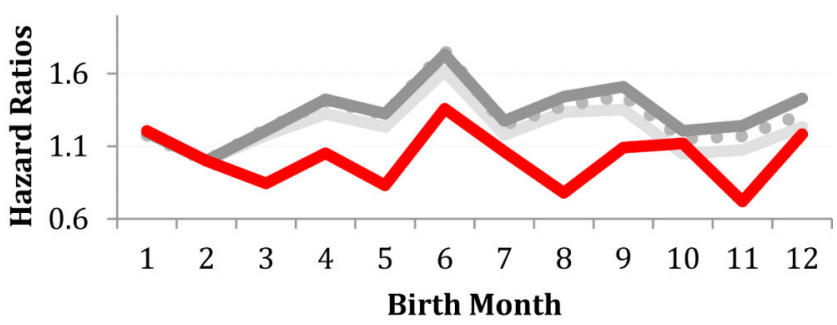

Mali

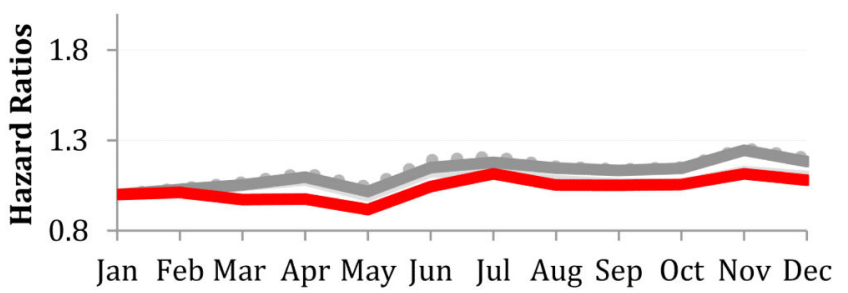

Birth Month

Model $1 \cdots \bullet$ Model 2 (Individual controls) Model 3 (All covariates)

Model 4 (Maternal Fixed-Effects) 


\section{Nigeria}

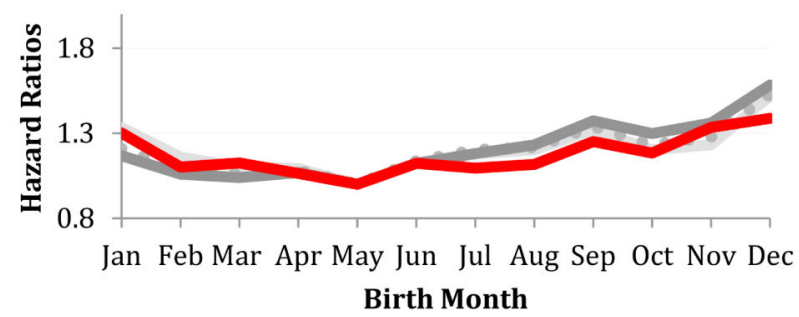

Uganda

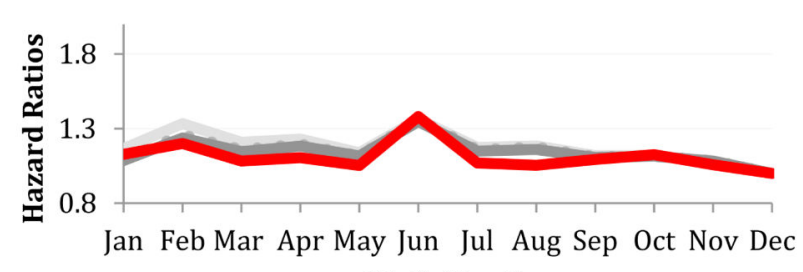
Birth Month

\section{Sierra Leone}

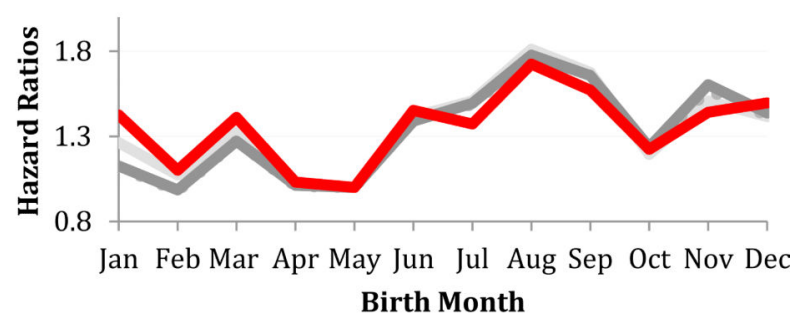

Zambia

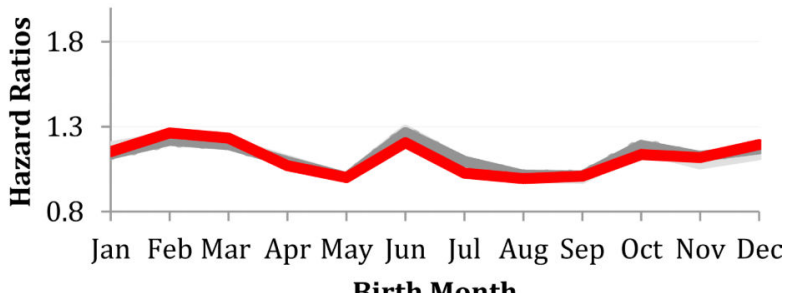

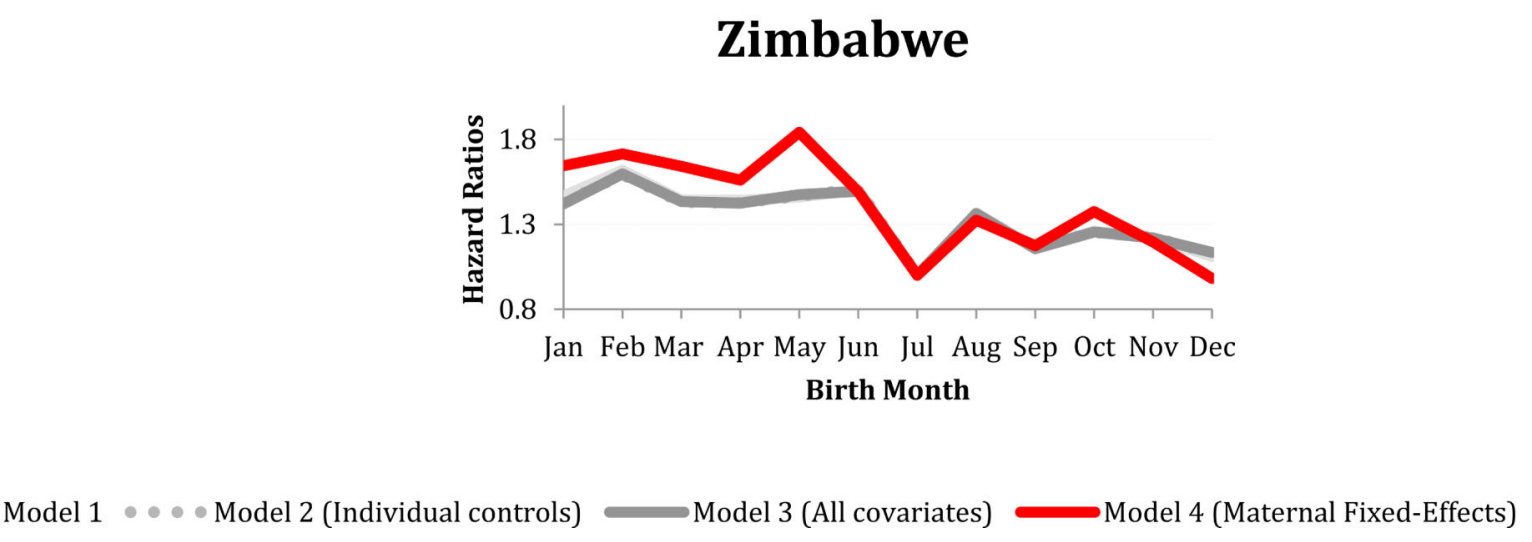

Figure 4.

Birth month hazard ratios from four different Cox Proportional Hazard Models. In the eleven countries displayed, the birth month effect remained jointly significant after adding individual level controls and controlling for maternal selection. 


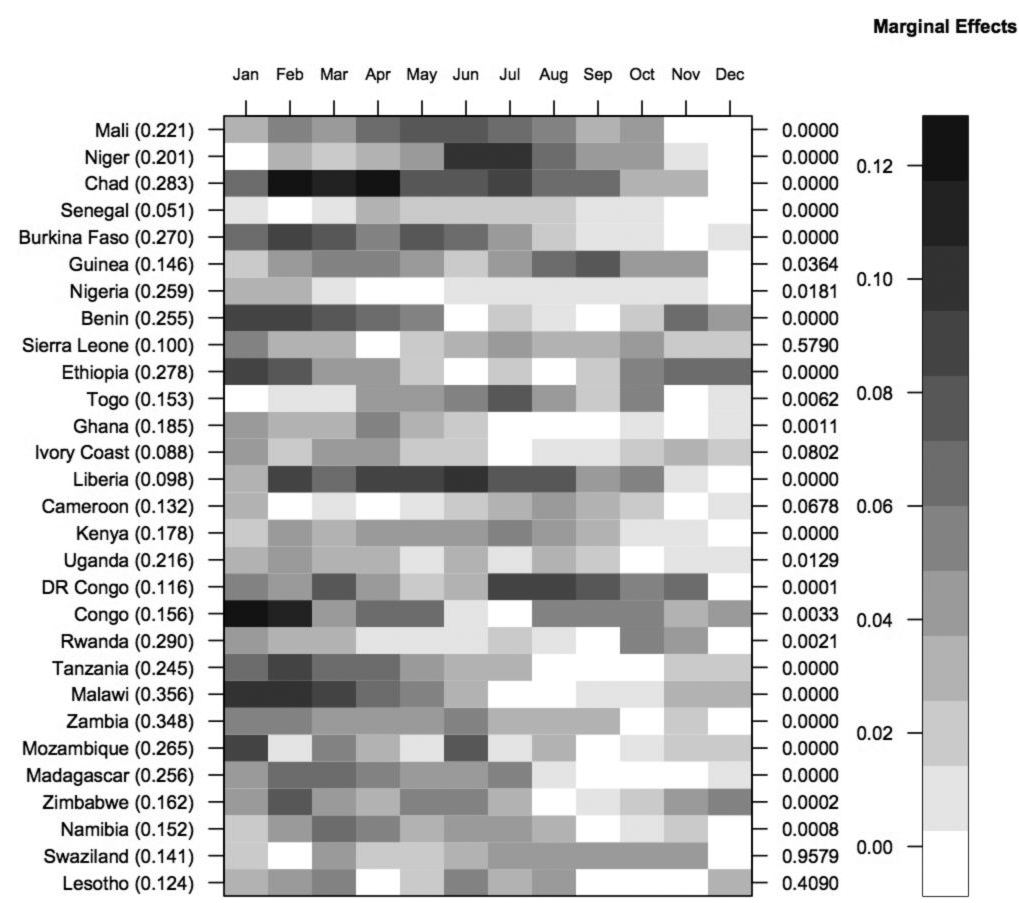

Figure 5.

Heat map showing marginal effects (i.e., differences between the predicted probabilities of being stunted) for each birth month relative to a reference month. For each country, the reference month is the month associated with the lowest predicted probability of being stunted. The magnitude of the marginal effects ranged from 0 percentage points (white) to 12 percentage points (black). Countries are ordered north/south and east/west. On the right axis, the p-values from the joint significance tests for birth month are presented. 


\section{Benin}

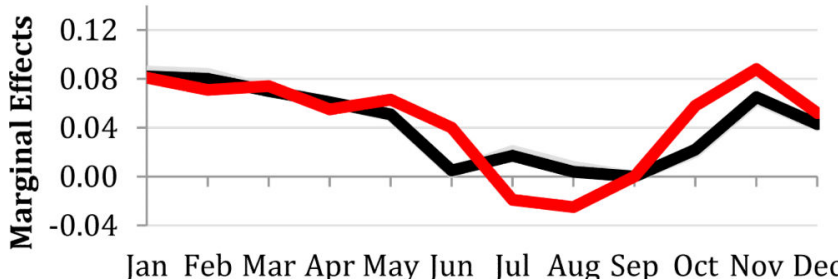

Birth Month

\section{Malawi}

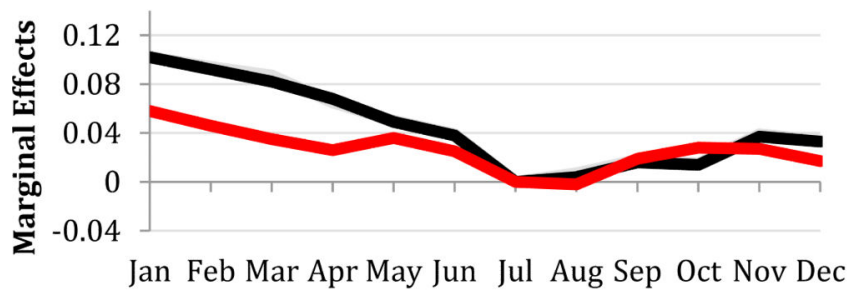

Birth Month
Madagascar

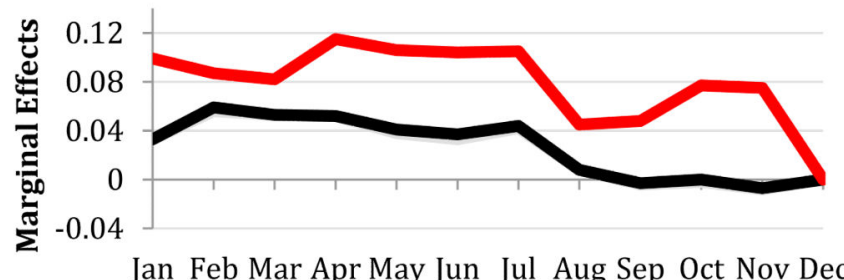

Birth Month

\section{Tanzania}

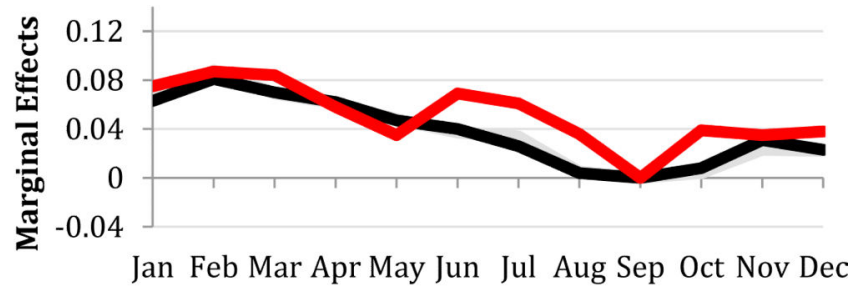

Birth Month

\section{Zambia}

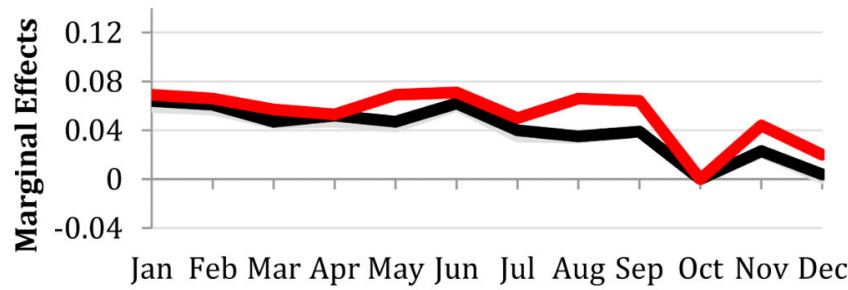

Birth Month

Model 1 (Individual Controls) $\longrightarrow$ Model 2 (All Controls) $\quad$ Model 3 (Maternal Fixed-Effects)

Figure 6.

Marginal effects for each birth month on the likelihood of being stunted from three different logistic models. These five countries are the only ones in which birth month remained jointly significant after running fixed effects model (i.e., controlling for observed and unobserved maternal selection). The birth month coefficients in Model 1 and 2 are very similar. 
Table 1

Summary statistics and data quality measure for the sample of 30 sub-Saharan African countries included in the analysis of under-five mortality.

\begin{tabular}{|c|c|c|c|c|c|c|c|c|c|}
\hline \multirow[b]{2}{*}{ Country } & \multirow[b]{2}{*}{$\mathbf{N}$} & \multirow{2}{*}{$\begin{array}{r}\text { Data } \\
\text { quality } \\
\text { (\% obs } \\
\text { dropped } \\
\text { due to } \\
\text { imputed } \\
\text { birth } \\
\text { date) } \\
\end{array}$} & \multirow{2}{*}{$\begin{array}{r}\begin{array}{r}\text { Prob } \\
\text { of }\end{array} \\
\text { deaths } \\
\text { under } \\
\text { five } \\
\end{array}$} & \multirow{2}{*}{$\begin{array}{c}\text { Sex } \\
\\
\text { \% male }\end{array}$} & \multicolumn{3}{|c|}{ Mother's education level } & \multicolumn{2}{|c|}{ Household type } \\
\hline & & & & & $\%$ no education & $\%$ some primary & $\%$ some secondary & \% urban & $\begin{array}{c}\% \\
\text { employed } \\
\text { in } \\
\text { agriculture }\end{array}$ \\
\hline Benin & 41,442 & 19.2 & 10.4 & 50.6 & 76.0 & 17.1 & 6.88 & 33.3 & 62.5 \\
\hline Burkina Faso & 36,824 & 16.9 & 14.5 & 51.0 & 86.6 & 9.2 & 4.22 & 21.7 & 78.0 \\
\hline Cameroon & 26,809 & 9.0 & 11.4 & 50.2 & 29.0 & 42.4 & 28.60 & 42.1 & 54.8 \\
\hline Chad & 24,207 & 4.3 & 16.4 & 50.2 & 75.7 & 19.1 & 5.13 & 40.0 & 61.8 \\
\hline Congo & 8,615 & 2.0 & 10.0 & 50.8 & 8.4 & 33.9 & 57.70 & 59.9 & 37.4 \\
\hline DR Congo & 16,113 & 1.9 & 13.6 & 50.5 & 24.8 & 42.5 & 32.70 & 40.2 & 63.2 \\
\hline Ivory Coast & 20,621 & 16.0 & 11.2 & 50.3 & 66.2 & 24.2 & 9.54 & 43.3 & 44.0 \\
\hline Ethiopia & 40,079 & 4.0 & 13.6 & 51.2 & 80.2 & 13.4 & 6.43 & 15.0 & 80.0 \\
\hline Ghana & 30,751 & 9.9 & 9.5 & 51.0 & 43.5 & 33.3 & 23.20 & 28.9 & 60.4 \\
\hline Guinea & 14,329 & 43.3 & 10.9 & 51.4 & 83.6 & 9.0 & 7.34 & 27.7 & 62.8 \\
\hline Kenya & 57,822 & 3.0 & 8.6 & 50.5 & 21.7 & 57.4 & 20.90 & 18.6 & 45.3 \\
\hline Lesotho & 6,874 & 0.7 & 9.4 & 50.6 & 3.6 & 66.4 & 30.00 & 20.0 & 39.1 \\
\hline Liberia & 19,643 & 6.5 & 14.9 & 51.2 & 59.1 & 25.9 & 15.00 & 35.5 & 32.0 \\
\hline Madagascar & 52,840 & 7.5 & 8.3 & 50.9 & 22.7 & 52.0 & 25.30 & 28.1 & 73.6 \\
\hline Malawi & 49,764 & 1.3 & 15.7 & 50.5 & 33.1 & 59.8 & 7.04 & 16.1 & 63.5 \\
\hline Mali & 74,153 & 8.4 & 18.8 & 50.4 & 84.9 & 10.9 & 4.19 & 26.5 & 67.2 \\
\hline Mozambique & 29,121 & 12.0 & 13.9 & 49.9 & 40.1 & 55.4 & 4.49 & 33.7 & 67.4 \\
\hline Namibia & 24,207 & 2.3 & 6.7 & 50.2 & 16.4 & 39.8 & 43.80 & 36.9 & 18.0 \\
\hline Niger & 40,796 & 13.7 & 19.1 & 50.9 & 85.3 & 10.2 & 4.53 & 29.6 & 57.9 \\
\hline Nigeria & 89,049 & 5.9 & 14.1 & 50.9 & 52.5 & 24.5 & 23.00 & 29.0 & 49.7 \\
\hline Rwanda & 41,038 & 2.9 & 15.3 & 50.6 & 36.3 & 54.5 & 9.24 & 18.2 & 85.0 \\
\hline Senegal & 46,613 & 14.8 & 11.2 & 50.9 & 78.0 & 16.3 & 5.69 & 33.4 & 44.4 \\
\hline Sierra Leone & 11,212 & 2.1 & 14.2 & 50.2 & 75.4 & 12.1 & 12.50 & 33.3 & 62.0 \\
\hline South Africa & 10,178 & 2.0 & 4.9 & 50.4 & 9.9 & 32.2 & 57.90 & 45.8 & 0.5 \\
\hline Swaziland & 5,318 & 0.4 & 10.0 & 51.1 & 11.1 & 36.3 & 52.60 & 27.2 & 12.8 \\
\hline Tanzania & 60,873 & 5.5 & 10.8 & 50.5 & 31.3 & 61.7 & 6.87 & 18.5 & 73.1 \\
\hline Togo & 14,469 & 27.9 & 8.9 & 50.8 & 60.8 & 29.6 & 9.53 & 26.3 & 46.8 \\
\hline Uganda & 49,971 & 2.4 & 13.1 & 49.8 & 29.0 & 58.1 & 12.80 & 19.8 & 70.0 \\
\hline Zambia & 48,842 & 1.1 & 14.7 & 49.7 & 16.1 & 63.8 & 20.10 & 33.7 & 55.4 \\
\hline Zimbabwe & 31,377 & 0.3 & 7.2 & 50.4 & 12.7 & 51.7 & 35.60 & 24.5 & 35.8 \\
\hline
\end{tabular}

Biodemography Soc Biol. Author manuscript; available in PMC 2016 January 05. 


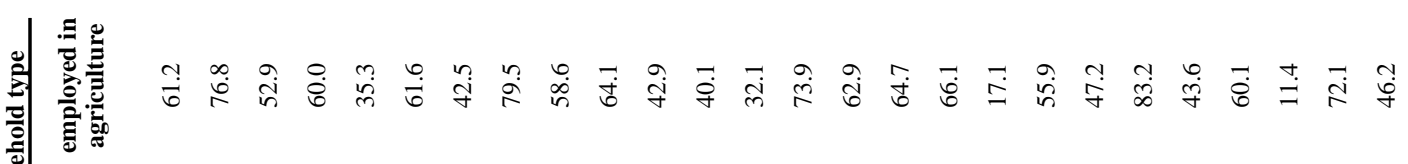

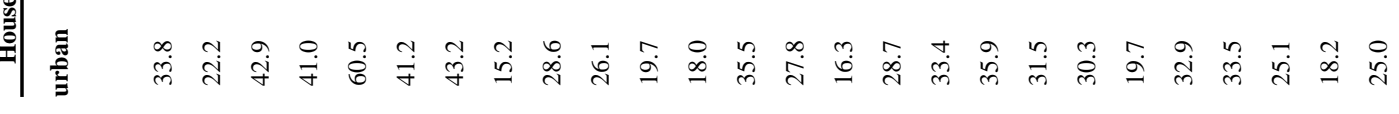

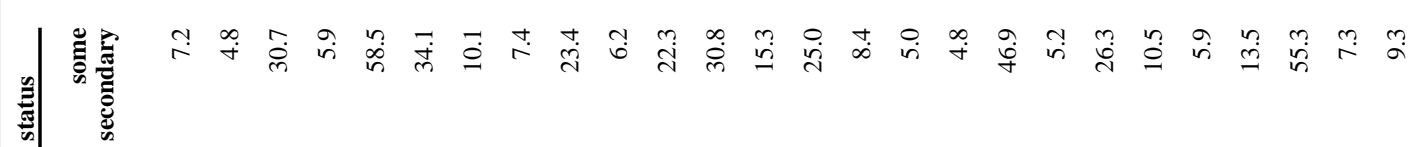

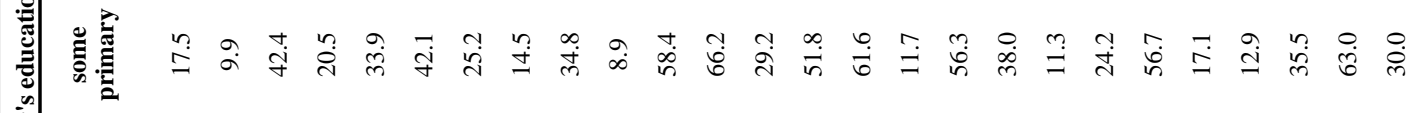
|⿹丁口⿹

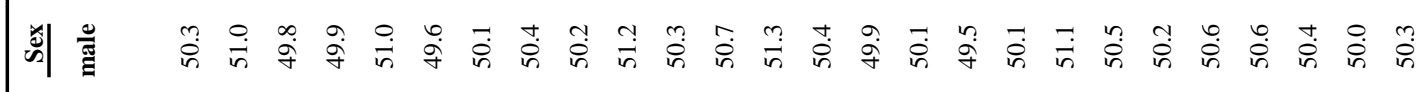

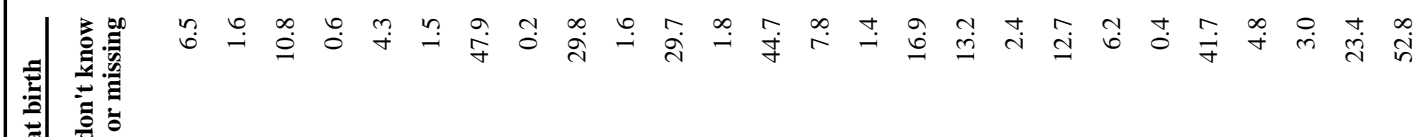

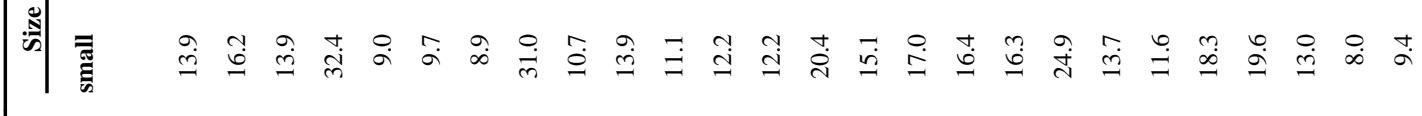
| 흘

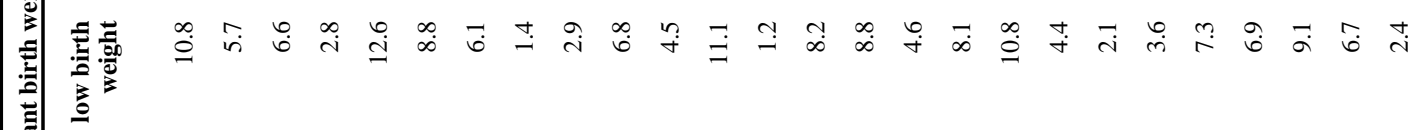

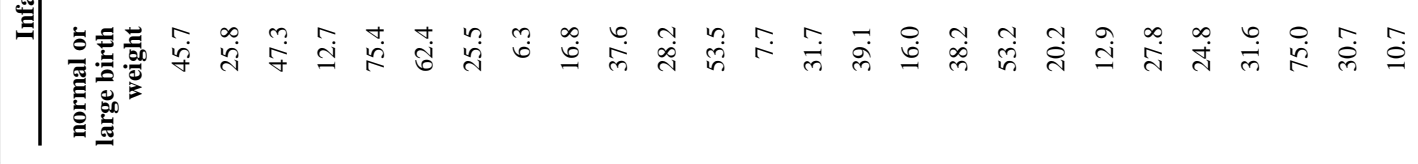

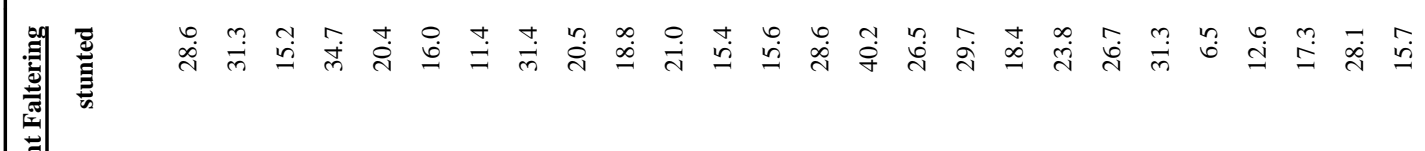

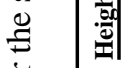

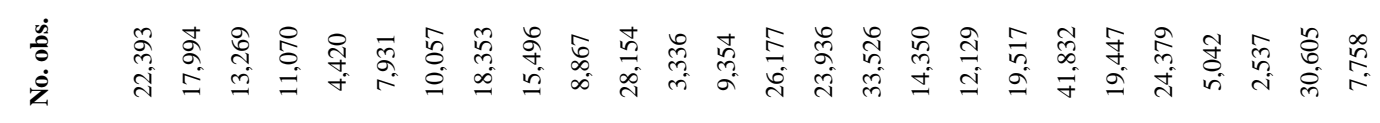

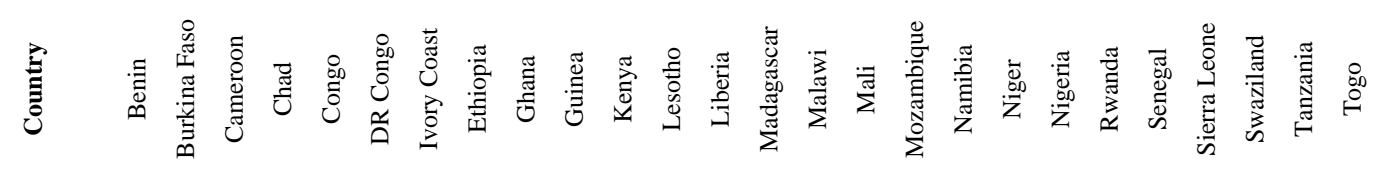




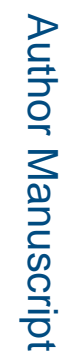



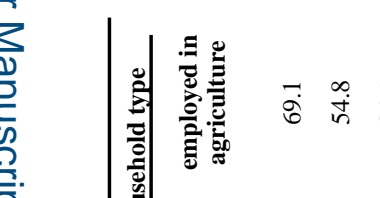

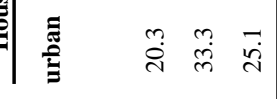

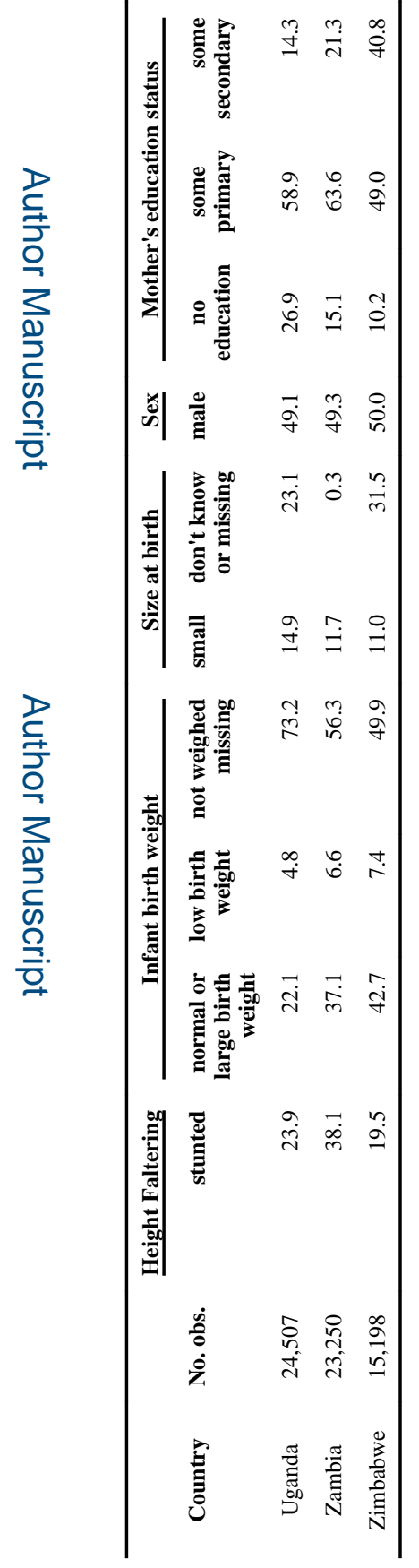

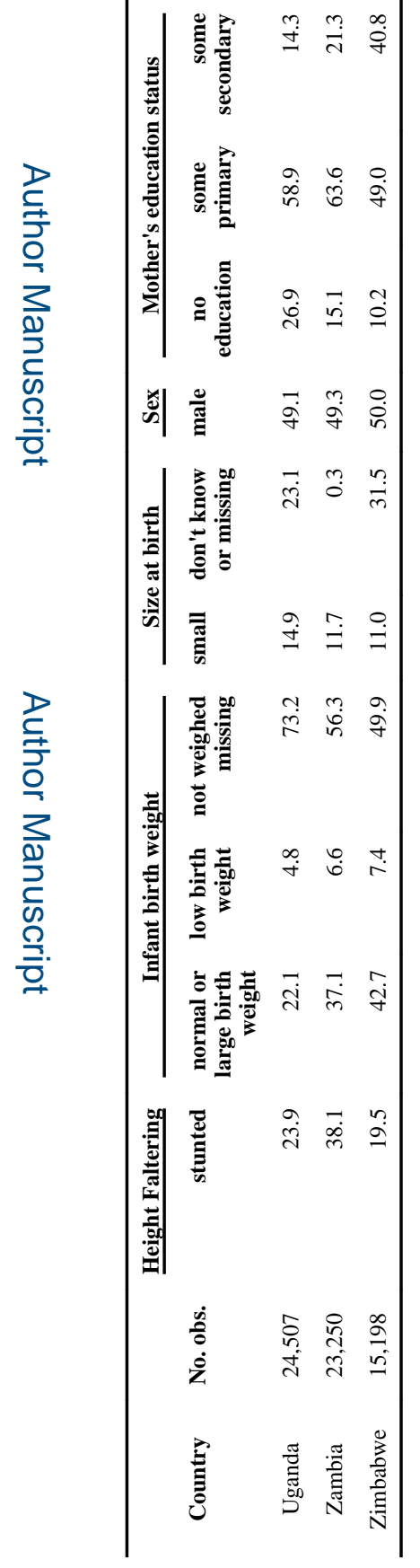

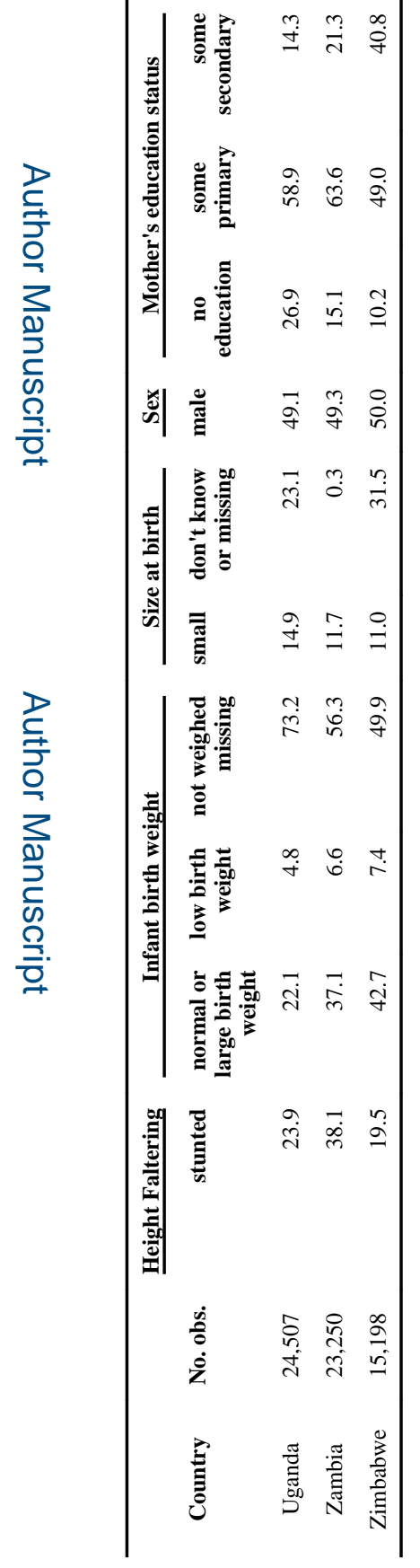

